\title{
Altered expression of cytokeratin 7 and CD117 in transitional mucosa adjacent to human colorectal cancer
}

\author{
HIDEAKI KIGASAWA $^{1,2}$, MASACHIKA FUJIWARA ${ }^{1}$, JUN ISHII ${ }^{1}$, TOMOHIRO CHIBA $^{1}$, \\ YUICHI TERADO ${ }^{1}$, HIROAKI SHIMOYAMADA ${ }^{1}$, MAKOTO MOCHIZUKI ${ }^{1}$, \\ OSAMU KITAMURA ${ }^{2}$, HIROSHI KAMMA ${ }^{1}$ and YASUO OHKURA ${ }^{1}$ \\ Departments of ${ }^{1}$ Pathology and ${ }^{2}$ Forensic Medicine, Kyorin University School of Medicine, Mitaka, Tokyo 181-8611, Japan
}

Received January 8, 2016; Accepted March 9, 2017

DOI: 10.3892/ol.2017.6156

\begin{abstract}
The multi-step progression of colorectal cancer through precancerous lesions (adenoma and dysplasia) is associated with cumulative molecular alterations, a number of which have also been demonstrated to be present in morphologically normal transitional mucosa adjacent to colorectal cancer. The cytoskeletal protein cytokeratin 7 (CK7) and the receptor tyrosine kinase, KIT proto-oncogene receptor tyrosine kinase (CD117), encoded by the proto-oncogene c-Kit, are lacking in normal colorectal crypt epithelium and are aberrantly expressed in a subset of colorectal cancer. The aim of the present study was to evaluate the expression of CK7 and CD117 in morphologically normal transitional mucosa adjacent to colorectal cancer. Immunohistochemical staining for CK7 and CD117 was performed in the mucosa adjacent to five groups of surgically resected colorectal tumors [low-grade adenoma, high-grade adenoma, mucosal adenocarcinoma, small-sized invasive adenocarcinoma $(\leq 2 \mathrm{~cm})$ and large-sized invasive adenocarcinoma $(>2 \mathrm{~cm})]$. CK7 was expressed in the mucosa adjacent to a subset of colorectal tumors, and the positivity ratio increased according to tumor grade from low-grade adenoma up to small-sized invasive adenocarcinoma (61.2\%). However, the positivity ratio of CK7 in the mucosa adjacent to the large-sized invasive adenocarcinoma (25.0\%) was significantly lower compared with that of the next lower grade. CD117 was also expressed in the mucosa adjacent to a subset of colorectal tumors. In contrast to $\mathrm{CK} 7$, the positivity ratio of CD117 increased according to tumor grade from low-grade adenoma all the way through to the large-sized invasive adenocarcinoma (45.0\%). Based on these results, the mechanism of CK7 and CD117 expression in the transitional mucosa
\end{abstract}

Correspondence to: Dr Masachika Fujiwara, Department of Pathology, Kyorin University School of Medicine, 6-20-2 Shinkawa, Mitaka, Tokyo 181-8611, Japan

E-mail: masachi@ks.kyorin-u.ac.jp

Key words: colorectal cancer, mucosa adjacent to cancer, cytokeratin 7, KIT proto-oncogene receptor tyrosine kinase, immunohistochemistry, field cancerization, molecular crosstalk adjacent to colorectal cancer may be different, and analysis of their individual expression may provide novel insights into the development and progression of colorectal cancer.

\section{Introduction}

Human colorectal cancer has multiple steps of progression, and neoplastic conversion of the colorectal crypt epithelium is associated with cumulative alterations of numerous genes, proteins and molecular processes (1). Molecular changes associated with the earlier steps may be demonstrated in precancerous lesions, including adenoma and dysplasia, which occasionally coexist with overt cancer (1-3). Increasing data indicates that a number of these molecular alterations also occur in morphologically normal transitional mucosa adjacent to colorectal cancer, under the basic concept of either field cancerization (areas of preneoplastic status) (4-7) or molecular crosstalk between cancer and surrounding non-neoplastic tissues (8).

Cytokeratin $(\mathrm{CK}) 7$ is one of the intermediate filament proteins that constitute the cytoskeleton of numerous types of epithelial cells. Colorectal crypt epithelia and tumors derived from it are representative of tissue that is negative for CK7, and the coordinate expression pattern of $\mathrm{CK} 7$ negativity with CK20-positivity (CK7-/CK20+) is used for confirmation of the colorectal origin of metastatic tumors (9). A number of studies have noted aberrant expression of CK7 in a subset of colorectal cancer $(10,11)$.

The type III receptor tyrosine kinase, KIT proto-oncogene receptor tyrosine kinase (CD117), which is encoded by the c-kit proto-oncogene, is normally expressed in a variety of human tissues, including hematopoietic stem cells, melanocytes, mast cells, germ cells and interstitial cells of Cajal (12-24). CD117 is also expressed in human tumors, including myeloid leukemia, melanoma, glioblastoma, germ cell tumors, breast cancer, small cell lung cancer and gastrointestinal stromal tumors (GISTs) (24). CD117 is not expressed in the normal crypt epithelium in the colon and the rectum, but aberrant expression of CD117 has been reported in a subset of cancers (24).

CK7 and CD117 expression has been demonstrated not only in developed colorectal cancer, but also in adenoma and dysplasia $(2,3,24)$. To the best of our knowledge, however, the expression of CK7 and CD117 in morphologically normal 
transitional mucosa adjacent to colorectal cancer has not been investigated to date. The lack of this information prompted the authors of the present study to assess the expression of CK7 and CD117 in morphologically normal transitional mucosa adjacent to colorectal cancer.

\section{Materials and methods}

Patients and tissue specimens. The tissue specimens analyzed in the present study consisted of tissue from 76 lesions of low-grade adenoma (from 65 patients), 18 lesions of high-grade adenoma (from 17 patients), 12 lesions of mucosal adenocarcinoma (from 12 patients), 67 lesions of small-sized invasive adenocarcinoma ( $\leq 2 \mathrm{~cm}$ in maximum diameter extending to the submucosa or deeper; from 66 patients) and 20 lesions of large-sized invasive adenocarcinoma ( $>2 \mathrm{~cm}$ in maximum diameter extending to the submucosa or deeper; from 20 patients). The main clinical and pathological characteristics of the patients and the colorectal tumors are listed in Table I. The archival samples were retrieved from the database of Kyorin University Hospital (Tokyo, Japan). The cases were diagnosed and treated by surgical resection (colectomy) between January 2007 and December 2011. To simplify the interpretation of obtained results, patients with either preceding inflammatory bowel disease or hereditary backgrounds, including familial adenomatous polyposis, or who had received preoperative chemo- or radiotherapy, were excluded from the present study. Serrated adenomas and adenocarcinomas developed through serrated pathways were also excluded. The present study was approved by the Ethics Committee of Kyorin University, School of Medicine. The need for written, informed consent was waived due to the retrospective, non-interventional nature of the present study.

Tissue preparation and immunohistochemistry. Formalin-fixed and paraffin-embedded tissues from the aforementioned samples were used for immunohistochemical analysis. The samples were originally fixed in $4 \%$ phosphate-buffered formaldehyde at room temperature for 24 to $72 \mathrm{~h}$ and embedded in paraffin, according to routine procedures. From each sample, $4 \mu \mathrm{m}$ sections were cut, dried, dewaxed in xylene and rehydrated in descending alcohol series (100, 90 and $70 \%$, twice in each concentration). The subsequent immunohistochemical staining procedure was conducted using a semiautomatic staining machine (Ventana ES; Ventana Medical Systems, Inc., Oro Valley, AZ, USA) according to the manufacturer's protocol. The following primary antibodies were used for immunohistochemistry: Anti-human CK7 mouse monoclonal antibody (clone OV-TL 12/30; cat. no. M7018; dilution, 1:200; Dako; Agilent Technologies, Inc., Santa Clara, CA, USA) and anti-human CD117 rabbit polyclonal antibody (cat. no. A4502; dilution, 1:400; Dako; Agilent Technologies, Inc). Samples were incubated with these antibodies at $37^{\circ} \mathrm{C}$ for $16 \mathrm{~min}$. For reference, hematoxylin and eosin staining was performed on the same samples (Carrazzi's hematoxylin solution and $1 \%$ eosin $\mathrm{Y}$ ).

Evaluation of CK7 and CD117 expression in colorectal tumors, transitional mucosa adjacent to the tumor and distant normal mucosa. For each patient, the expression of CK7 and CD117 in tumor lesions, in transitional mucosa adjacent to the tumor and in distant normal mucosa was immunohistochemically evaluated under light microscope. For each area, 4 fields of view were assessed at magnification, x100.

The expression levels of the proteins were scored between 0 and $3+$ according to the extent of the immunoreactive glands. The scores $1+$ to $3+$ were defined as follows: $1+, 1-2$ consecutive glands; $2+, 3-5$ glands; and $3+, \geq 6$ glands. In solid or diffusely infiltrating tumors without gland formation, each $100 \mu \mathrm{m}$-size area was counted as one gland. Scores of $1+$ to $3+$ were considered as positive. Subjects without or with a few scattered immunoreactive cells were scored as 0 (negative). In cases of heterogeneous staining, areas of the highest reactivity were selected for scoring. All immunohistochemical staining was independently evaluated by two pathologists, and then consensus scores were adopted.

Statistical analysis. Staining data were analyzed using Statcel v.3 software (OMS, Tokorozawa, Japan; http://www. oms-publ.co.jp). The Mann-Whitney U-test was applied to determine the difference in the positivity rate for expression of CK7 and CD117. $\mathrm{P}<0.05$ was considered to indicate a statistically significant difference.

\section{Results}

Expression of CK7 in colorectal tumors, in transitional mucosa adjacent to the tumor and in distant normal mucosa. The immunohistochemical analysis of the expression of CK7 in the tumor, in transitional mucosa adjacent to the tumor and in distant normal mucosa is summarized in Table II. Regarding CK7 expression in the transitional mucosa adjacent to the tumor, a positive result (score of $1+$ to $3+$ ) was obtained in $7.9 \%(6 / 76)$ of low-grade adenomas, $11.1 \%$ (2/18) of high-grade adenomas, $50.0 \%(6 / 12)$ of mucosal adenocarcinomas, $61.2 \%$ (41/67) of small-sized invasive adenocarcinomas and $25.0 \%$ $(5 / 20)$ of large-sized invasive adenocarcinomas, irrespective of CK7 expression in the corresponding tumors. The CK7 positivity rate in the transitional mucosa adjacent to the tumor exhibited a stepwise increase according to the grade of the corresponding tumor, increasing from a low-grade adenoma through to a small-sized invasive adenocarcinoma (Fig. 1). However, in the large-sized invasive adenocarcinoma cases, the positivity rate for $\mathrm{CK} 7$ in the transitional mucosa adjacent to the tumor was significantly lower compared with the next lower tumor grades (Fig. 1). Representative images of the transitional areas revealed that expression of CK7 in the mucosa adjacent to the small-sized invasive adenocarcinoma (score 3+; positive) differed from that in the mucosa adjacent to the large-sized invasive adenocarcinoma (score 0; negative; Fig. 2).

As for CK7 expression in the tumor itself, CK7 was expressed in $1.3 \%$ (1/76) of low-grade adenomas, $5.6 \%(1 / 18)$ of high-grade adenomas, $8.3 \%$ (1/12) of mucosal adenocarcinomas, $10.4 \%$ (7/67) of small-sized invasive adenocarcinomas and $25.0 \%(5 / 20)$ of large-sized invasive adenocarcinomas. Distant normal mucosa was virtually negative for CK7 except for $3.0 \%$ (2/66) of small-sized invasive adenocarcinoma cases.

Expression of CD117 in colorectal tumors, transitional mucosa adjacent to the tumor and distant normal mucosa. The 
Table I. Characteristics of patients with colorectal adenoma or adenocarcinoma.

\begin{tabular}{lcccrr}
\hline Diagnosis & $\begin{array}{c}\text { Total number } \\
\text { of neoplasms, } n\end{array}$ & $\begin{array}{c}\text { Age, years } \\
\text { (mean, range) }\end{array}$ & $\begin{array}{c}\text { Male: } \\
\text { Female }\end{array}$ & $\begin{array}{c}\text { Left: } \\
\text { Right }\end{array}$ & $\begin{array}{c}\text { Size, mm } \\
\text { (mean, range) }\end{array}$ \\
\hline Low-grade adenoma & 76 & $72(47-91)$ & $42: 23$ & $41: 35$ & $8.2(3-36)$ \\
High-grade adenoma & 18 & $68(47-91)$ & $12: 5$ & $9: 9$ & $16.2(8-25)$ \\
Mucosal adenocarcinoma & 12 & $70(59-89)$ & $11: 1$ & $8: 4$ & $19.6(6-60)$ \\
Small-sized invasive adenocarcinoma & 67 & $70(37-88)$ & $40: 26$ & $41: 26$ & $16.3(7-20)$ \\
Large-sized invasive adenocarcinoma & 20 & $70(44-86)$ & $12: 8$ & $8: 12$ & $49.9(24-110)$ \\
\hline
\end{tabular}

Table II. Summary of cytokeratin 7 expression in adjacent mucosa, tumor and distant mucosa.

\begin{tabular}{|c|c|c|c|c|c|c|}
\hline \multirow[b]{2}{*}{ Diagnosis } & \multirow[b]{2}{*}{ Region } & \multirow[b]{2}{*}{$\mathrm{n}$} & \multicolumn{4}{|c|}{ Score } \\
\hline & & & 0 & $1+$ & $2+$ & $3+$ \\
\hline \multirow[t]{3}{*}{ Low-grade adenoma } & Adjacent mucosa & $76^{\mathrm{a}}$ & 70 & 4 & 2 & 0 \\
\hline & Tumor & $76^{\mathrm{a}}$ & 75 & 1 & 0 & 0 \\
\hline & Distant normal mucosa & 65 & 65 & 0 & 0 & 0 \\
\hline \multirow[t]{3}{*}{ High-grade adenoma } & Adjacent mucosa & $18^{\mathrm{a}}$ & 16 & 2 & 0 & 0 \\
\hline & Tumor & $18^{\mathrm{a}}$ & 17 & 1 & 0 & 0 \\
\hline & Distant normal mucosa & 17 & 17 & 0 & 0 & 0 \\
\hline \multirow[t]{3}{*}{ Mucosal adenocarcinoma } & Adjacent mucosa & 12 & 6 & 3 & 3 & 0 \\
\hline & Tumor & 12 & 11 & 0 & 1 & 0 \\
\hline & Distant normal mucosa & 12 & 12 & 0 & 0 & 0 \\
\hline \multirow[t]{3}{*}{ Small-sized invasive adenocarcinoma } & Adjacent mucosa & $67^{\mathrm{a}}$ & 26 & 24 & 10 & 7 \\
\hline & Tumor & $67^{\mathrm{a}}$ & 60 & 1 & 2 & 4 \\
\hline & Distant normal mucosa & 66 & 64 & 2 & 0 & 0 \\
\hline \multirow[t]{3}{*}{ Large-sized invasive adenocarcinoma } & Adjacent mucosa & 20 & 15 & 4 & 1 & 0 \\
\hline & Tumor & 20 & 15 & 1 & 1 & 3 \\
\hline & Distant normal mucosa & 20 & 20 & 0 & 0 & 0 \\
\hline
\end{tabular}

ancluding multiple tumors.

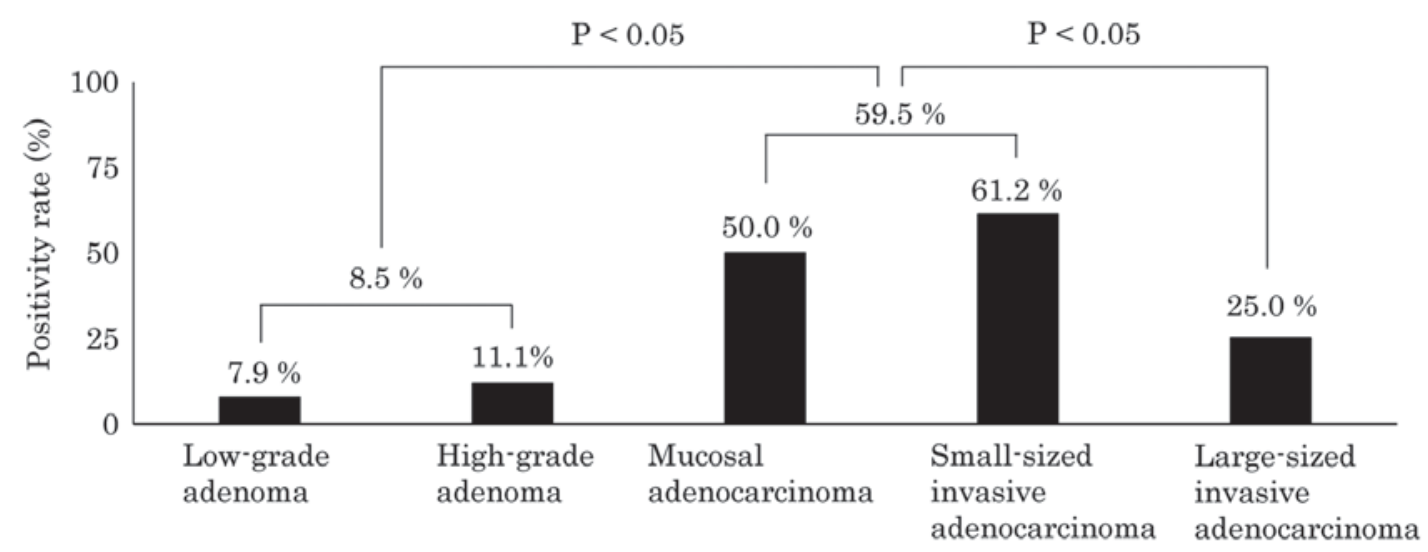

Figure 1. Schematic presentation of the cytokeratin 7 positivity rate in transitional mucosa adjacent to colorectal tumors.

results of immunohistochemical analysis of CD117 expression are summarized in Table III. Concerning CD117 expression in the transitional mucosa adjacent to the tumor, positive results (a score of $1+$ to $3+$ ) were obtained in $10.5 \%$ (8/76) of low-grade adenomas, $16.7 \%$ (3/18) of high-grade adenomas, $25.0 \%(3 / 12)$ of mucosal adenocarcinomas, $38.8 \%$ (26/67) of small-sized 


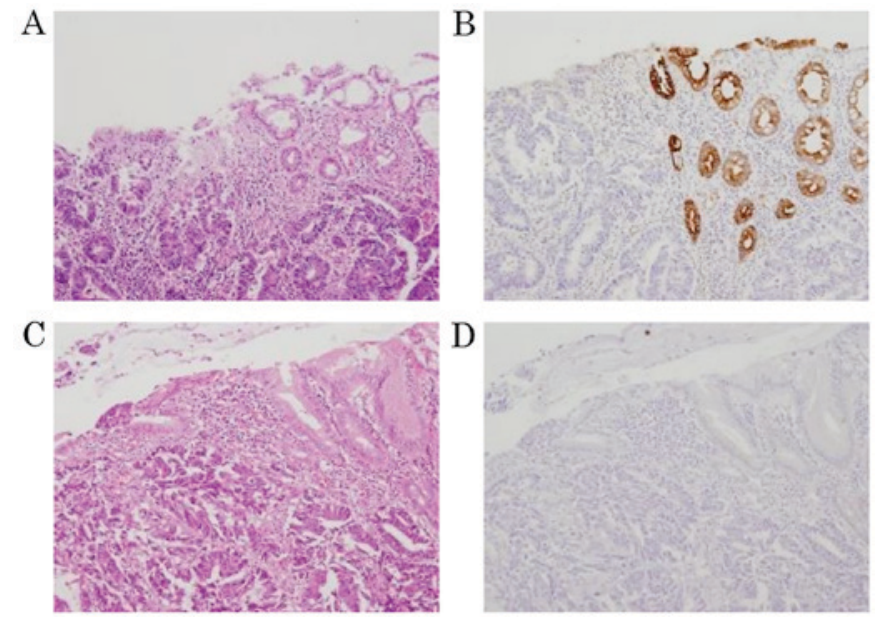

Figure 2. Representative images of the transitional area of small-sized and large-sized invasive adenocarcinoma. (A) Histological and (B) immunohistochemical staining for CK7 of small-sized invasive adenocarcinoma (C) Histological and (D) immunohistochemical staining for CK7 of large-sized invasive adenocarcinoma (original magnification, x100). CK7, cytokeratin 7.

invasive adenocarcinomas and $45.0 \%(9 / 20)$ of large-sized invasive adenocarcinomas, irrespective of CD117 expression in the corresponding tumors. In contrast to $\mathrm{CK} 7$, the positivity rate for $\mathrm{CD} 117$ in the transitional mucosa adjacent to the tumor increased stepwise according to tumor grade, from low grade adenoma all the way through to large-sized invasive adenocarcinoma cases, and there was a significant difference in CD117 expression in this location between the adenoma group and the adenocarcinoma group $(\mathrm{P}<0.05$; Fig. 3). Representative images of the transitional areas demonstrated expression of CD117 in the adjacent mucosa of small-sized invasive adenocarcinoma (score 3+; positive) and large-sized invasive adenocarcinoma (score 3+; positive; Fig. 4).

As for CD117 expression in the tumor itself, CD117 was expressed in $25.0 \%$ (19/76) of low-grade adenoma, $33.3 \%(6 / 18)$ of high-grade adenoma, $8.3 \%$ (1/12) of mucosal adenocarcinoma, $14.9 \%(10 / 67)$ of small-sized invasive adenocarcinoma and $5.0 \%(1 / 20)$ of large-sized invasive adenocarcinoma. Notably, the tumor positivity rate for CD117 was significantly increased in the adenoma group compared with the adenocarcinoma group $(\mathrm{P}<0.05)$. In distant normal mucosa, CD117 expression was detected only in a small percentage of low-grade adenoma cases $[6.2 \%(4 / 65)]$ and small-sized invasive adenocarcinoma cases $[7.6 \%(5 / 66)]$.

\section{Discussion}

In the present study, CK7 and CD117 were demonstrated to be expressed in the transitional mucosa adjacent to colorectal tumors. In adenoma, mucosal adenocarcinoma and small-sized invasive adenocarcinoma cases, the positivity ratio of CK7 and CD117 increased in a stepwise manner according to tumor grade. Regarding CK7 and CD117 expression in large-sized invasive adenocarcinoma cases, there was a difference between whether expression was increased (CD117) or decreased (CK7) compared with the expression in small-sized invasive carcinoma cases. The results of the present study indicated that the expression mechanisms of
CK7 and CD117 were different in the transitional mucosa adjacent to colorectal cancer.

The positivity ratio for CK7 in the transitional mucosa adjacent to the tumor was lower in large-sized invasive adenocarcinoma cases compared with in mucosal and small-sized invasive adenocarcinoma cases. This lower CK7 positivity ratio in the large-sized invasive adenocarcinoma cases may be partially explained by the encroachment of cancer cells into morphologically normal, CK7-positive mucosa, which predisposes the tissue to cancerous development.

Cytokeratins are a family of cytoplasmic structural proteins that have been described in human epithelium, which demonstrate variable expression depending on the type of tissue and its differentiation status $(25,26)$. CK7 is expressed in several simple ductal and glandular epithelia, including the lung, breast, bile and pancreatic ducts, urinary tracts, ovary and endometrium (27). In contrast, CK7 expression is generally lacking in normal mucosa of the colon, rectum and, correspondingly, in colorectal adenoma and adenocarcinoma $(11,28)$. The biological significance of CK7 expression remains largely unknown. Kirchner et al (29) reported that CK7 is aberrantly expressed in boundary mucosa adjacent to gastric cancer, and proposed that this expression may reflect transient dedifferentiation, which is associated with metaplastic and dysplastic change in the gastritis-cancer sequence. The same transient dedifferentiation step may occur in the transitional mucosa adjacent to colorectal cancer.

Within the concept of field cancerization, also termed the field effect or the field defect, morphologically normal mucosa surrounding the cancer is considered to be biologically different compared with the normal mucosa of subjects with no malignant or premalignant lesions. This concept was first introduced by Slaughter et al (30) to explain the presence of multifocal oral squamous cell carcinomas that developed out of a field of precancerous change, and the concept has now been applied to a variety of organs, including the lung, breast, esophagus, stomach and colon (31). In the colon and rectum, field cancerization has been described in cancer associated with chronic inflammatory bowel disease, including ulcerative colitis and Crohn's disease (32-35), and also in sporadic cases $(5,6,31)$. Field cancerization has not been well defined in molecular terms; however, previous studies have proposed mutated genes, including tumor protein p53 and DNA methylation genes, as candidate mediators of the field cancerization in colorectal cancer $(4,6,31)$. Therefore, aberrant expression of CK7 is considered to be another candidate marker for field cancerization in colorectal cancer.

The areas of CK7-positive crypts observed in the present study were localized close to the tumor, and the positive areas were smaller than the fields demonstrated by other studies that used different markers $(5,7,36)$. Facista et al (37) hypothesized that the molecular alterations associated with field cancerization progress outwards, and that the most extensive regions reflect the earliest event in carcinogenesis. If this is the case, then aberrant expression of CK7 would be the latest event for tumorigenesis in the colon and rectum.

With respect to CK7 expression in the tumors, colorectal cancers commonly lack CK7 expression, and positive immunostaining for CK7 in metastatic tumors supports the exclusion of a colorectal origin for these tumors $(10,11,26,28)$. 
Table III. Summary of KIT proto-oncogene receptor tyrosine kinase expression in adjacent mucosa, tumor and distant mucosa.

\begin{tabular}{|c|c|c|c|c|c|c|}
\hline \multirow[b]{2}{*}{ Diagnosis } & \multirow[b]{2}{*}{ Region } & \multirow[b]{2}{*}{$\mathrm{n}$} & \multicolumn{4}{|c|}{ Score } \\
\hline & & & 0 & $1+$ & $2+$ & $3+$ \\
\hline \multirow[t]{3}{*}{ Low-grade adenoma } & Adjacent mucosa & $76^{\mathrm{a}}$ & 68 & 2 & 2 & 4 \\
\hline & Tumor & $76^{\mathrm{a}}$ & 57 & 5 & 7 & 7 \\
\hline & Distant normal mucosa & 65 & 61 & 0 & 0 & 4 \\
\hline \multirow[t]{3}{*}{ High-grade adenoma } & Adjacent mucosa & $18^{\mathrm{a}}$ & 15 & 0 & 0 & 3 \\
\hline & Tumor & $18^{\mathrm{a}}$ & 12 & 0 & 2 & 4 \\
\hline & Distant normal mucosa & 17 & 17 & 0 & 0 & 0 \\
\hline \multirow[t]{3}{*}{ Mucosal adenocarcinoma } & Adjacent mucosa & 12 & 9 & 0 & 0 & 3 \\
\hline & Tumor & 12 & 11 & 0 & 1 & 0 \\
\hline & Distant normal mucosa & 12 & 12 & 0 & 0 & 0 \\
\hline \multirow[t]{3}{*}{ Small-sized invasive adenocarcinoma } & Adjacent mucosa & $67^{\mathrm{a}}$ & 41 & 6 & 4 & 16 \\
\hline & Tumor & $67^{\mathrm{a}}$ & 57 & 0 & 3 & 7 \\
\hline & Distant normal mucosa & 66 & 61 & 0 & 0 & 5 \\
\hline \multirow[t]{3}{*}{ Large-sized invasive adenocarcinoma } & Adjacent mucosa & 20 & 11 & 3 & 2 & 4 \\
\hline & Tumor & 20 & 19 & 0 & 0 & 1 \\
\hline & Distant normal mucosa & 20 & 20 & 0 & 0 & 0 \\
\hline
\end{tabular}

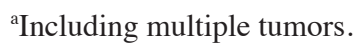

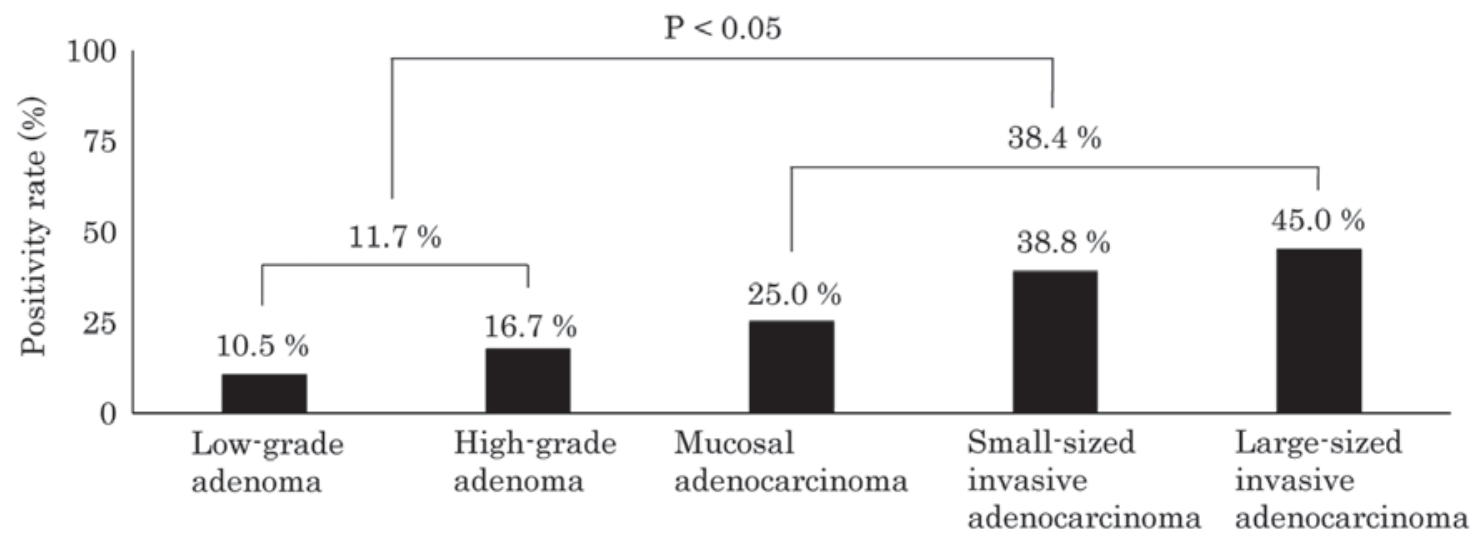

Figure 3. Schematic presentation of the KIT proto-oncogene receptor tyrosine kinase positivity rate in transitional mucosa adjacent to colorectal tumors.

However, not all colorectal cancers lack CK7 expression, and CK7 positivity in colorectal cancers has been reported to range from $0-16 \%$ (reviewed by Harbaum) (38). CK7 expression in colorectal cancer was reported to be associated with high-grade, right-sided tumors (39). In the present study, CK7 expression was observed in $2.1 \%$ of colorectal adenomas and $13.1 \%$ of carcinomas, and the frequency of expression increased according to the tumor grade. These results are in line with those of other previous studies $(9,38,39)$. However, no association was observed between CK-7-positivity and the location of the tumor (data not shown).

In contrast to $\mathrm{CK} 7$, the positivity rate for $\mathrm{CD} 117$ in transitional mucosa adjacent to the large-sized invasive adenocarcinoma cases was increased compared with its expression in the mucosa adjacent to preinvasive and small-sized invasive tumors. Based on this result, expression of CD117 in transitional mucosa adjacent to colorectal cancer may be secondarily induced by the corresponding cancer rather than predisposing the tissue to cancerous development.

The proto-oncogene c-kit encodes a transmembrane tyrosine kinase receptor CD117, which is associated with the platelet-derived growth factor PDGF/colony stimulating factor 1 (c-fms) receptor subfamily $(40,41)$. The ligand for CD117 is stem cell factor (SCF), which activates the tyrosine kinase activity of CD117 via homodimerisation and autophosphorylation of the receptor at specific tyrosine residues in the intracellular domain of the receptor $(42,43)$. CD117 is normally expressed in a variety of human tissues, including hematopoietic stem cells, melanocytes, mast cells, germ cells and interstitial cells of Cajal (44). Immunohistochemical analyses indicated that the localization of CD117 protein in the normal colon was restricted to interstitial cells of Cajal 


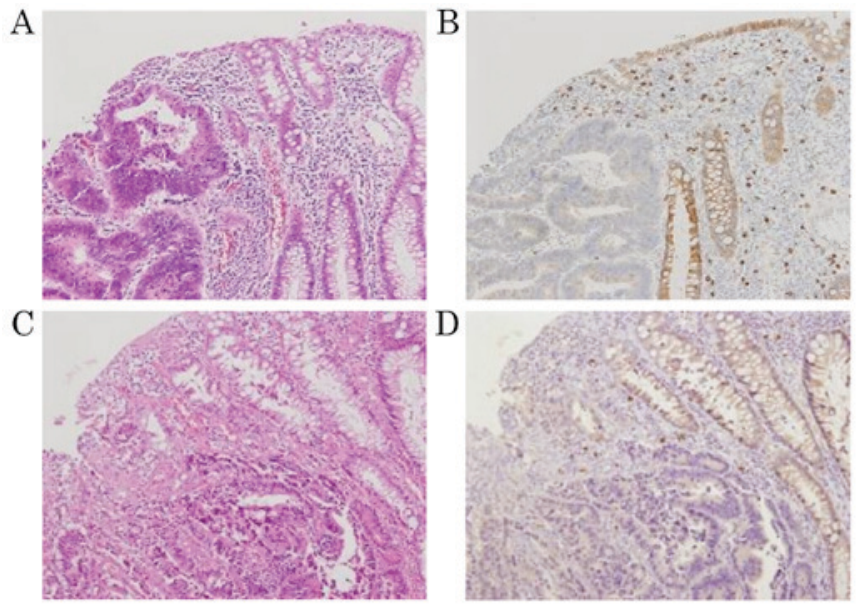

Figure 4. Representative images of the transitional area of small-sized and large-sized invasive adenocarcinoma. (A) Histological and (B) immunohistochemical staining for CD117 of small-sized invasive adenocarcinoma. (C) Histological and (D) immunohistochemical staining for CD117 of large-sized invasive adenocarcinoma (original magnification, x100). CD117, KIT proto-oncogene receptor tyrosine kinase.

scattered in the stroma, whereas the non-neoplastic epithelium was always negative (45).

Abnormal levels of CD117 expression have been observed in a variety of human tumors, including GISTs, myeloid leukemia, melanoma, glioblastoma, germ cell cancer, breast cancer, prostatic cancer and small cell lung cancer $(24,44,45)$. Two general mechanisms of CD117 activation in these tumors have been described: Acquisition of activating mutations that result in constitutive ligand-independent CD117 phosphorylation, and autocrine or paracrine stimulation of the receptor by its ligand SCF (24).

Data concerning the expression of CD117 in colorectal cancer are controversial (24,44-46). Overall, as determined by immunohistochemistry, the expression of CD117 is rare, and CD117 expression has been detected in only 1.6-25\% of colorectal carcinomas examined (24,44-48). Colorectal cancer with overexpression of CD117 did not demonstrate c-kit gene mutations in hot spot regions (44). The majority of CD117-positive carcinomas co-expressed SCF, and the existence of autocrine/paracrine mechanisms has been proposed $(24,49,50)$.

There is increasing data to support a central function for the tumor microenvironment in the mechanisms for the progression of colorectal cancer $(8,51,52)$. The tumor microenvironment is composed not only of a heterogeneous population of stromal cells, including fibroblasts and immune cells, extracellular matrix and secreted factors within the tumor bulk, but also of the adjacent non-tumor mucosa, which interacts and communicates with the cancer. This molecular crosstalk is mediated thorough cytokines and other factors secreted by the tumor, which activate receptors in the adjacent colonic tissue; and vice versa, providing novel insights into the micro-ecology of colorectal tumorigenesis.

In the present study, CD117 expression in transitional mucosa adjacent to colorectal cancer was considered to be the result of paracrine stimulation by SCF secreted by the cancer. CD117 was not included in genes activated in the mucosa adjacent to colorectal cancer in an extensive transcriptomic analysis performed by Sanz-Pamplona et al (8). The results of the present study indicated that molecular crosstalk through SCF and CD117 may be rather weak, and be restricted to the mucosa just beside the edge of the colorectal tumor.

In the colorectal tumors of the present study, the expression of CD117 in carcinoma was less frequent than in adenoma (12.1 and 26.6\%, respectively). This result concurred with that reported by Bellone et al (24), who also described lower CD117 expression in carcinoma $(10.6 \%)$ compared with adenoma (12.5\%). Similarly, in the uterus, CD117 was reported to be expressed less frequently in endometrial carcinoma than in endometrial hyperplasia (53). Mutational switches for tumor growth other than the SCF-CD117 autocrine/paracrine system may be turned on in the course of progression of these tumors.

Although antibodies for CK7 and CD117 are conventionally used in daily diagnostic practice, they may provide novel insights into the development and progression of colorectal cancer (9-24). A potential weakness of the present study was that it was conducted retrospectively and dealt with archival histopathological specimens. Further prospective studies, including those using cancer-grafted model animals, may provide more evidence to support the results of the present study.

In conclusion, the present study demonstrated that CK7 and CD117 were expressed in the transitional mucosa adjacent to colorectal tumors. However, their expression mechanisms were considered to be different. From the practical point of view, staining for CK7, as a marker for field cancerization, may be used for evaluation of the surgical margin and for prediction of the risk of local recurrence. An approach for analysis of the molecular crosstalk between receptors, including CD117 and signaling proteins secreted by the tumor, may be useful in order to gain insight into the maintenance of the microenvironment of colorectal cancer. Disruption of this intricate molecular network of cell-cell communication may be a novel therapeutic strategy for the treatment of colorectal cancer.

\section{Acknowledgements}

The authors would like to thank Ms. Michiru Umino (Department of Pathology, Kyorin University School of Medicine, Mitaka, Japan) or her excellent technical assistance.

\section{References}

1. Cho KR and Vogelstein B: Genetic alterations in the adenoma-carcinoma sequence. Cancer 70 (6 Suppl): S1727-S1731, 1992.

2. Tatsumi N, Kushima R, Vieth M, Mukaisho K, Kakinoki R, Okabe H, Borchard F, Stolte M, Okanoue T and Hattori T: Cytokeratin 7/20 and mucin core protein expression in ulcerative colitis-associated colorectal neoplasms. Virchows Arch 448: 756-762, 2006.

3. Stenling R, Lindberg J, Rutegård J and Palmqvist R: Altered expression of CK7 and CK20 in preneoplastic and neoplastic lesions in ulcerative colitis. APMIS 115: 1219-1226, 2007.

4. Baytner S, Mitmaker B, Gordon PH and Wang E: Immunohistochemical expression of mutant p53 oncogene in transitional mucosa adjacent to human colon cancer. Clin Invest Med 16: 379-385, 1993.

5. Jothy S, Ślesak B, Harłozińska A, Lapińska J, Adarniak J and Rabczyński J: Field effect of human colon carcinoma on normal mucosa: Relevance of carcinoembryonic antigen expression. Tumour Biol 17: 58-64, 1996. 
6. Shen L, Kondo Y,Rosner GL, Xiao L,HernandezNS, Vilaythong J, Houlihan PS, Krouse RS, Prasad AR, Einspahr JG, et al: MGMT promoter methylation and field defect in sporadic colorectal cancer. J Natl Cancer Inst 97: 1330-1338, 2005.

7. Hawthorn L, Lan L and Mojica W: Evidence for field effect cancerization in colorectal cancer. Genomics 103: 211-221, 2014

8. Sanz-Pamplona R, Berenguer A, Cordero D, Molleví DG, Crous-Bou M, Sole X, Paré-Brunet L, Guino E, Salazar R, Santos C, et al: Aberrant gene expression in mucosa adjacent to tumor reveals a molecular crosstalk in colon cancer. Mol Cancer 13: 46, 2014.

9. Bayrak R, Yenidünya S and Haltas H: Cytokeratin 7 and cytokeratin 20 expression in colorectal adenocarcinomas. Pathol Res Pract 207: 156-160, 2011.

10. Moll R, Franke WW, Schiller DL, Geiger B and Krepler R: The catalog of human cytokeratins: Patterns of expression in normal epithelia, tumors and cultured cells. Cell 31: 11-24, 1982.

11. Ramaekers F, van Niekerk C, Poels L, Schaafsma E, Huijsmans A, Robben H, Schaart G and Vooijs P: Use of Monoclonal antibodies to keratin 7 in the differential diagnosis of adenocarcinomas. Am J Pathol 136: 641-655, 1990.

12. Wang C, Curtis JE, Geissler EN, McCulloch EA and Minden MD: The expression of the proto-oncogene C-kit in the blast cells of acute myeloblastic leukemia. Leukemia 3: 699-702, 1989.

13. Ikeda H, Kanakura Y, Tamaki T, Kuriu A, Kitayama H, Ishikawa J, Kanayama Y, Yonezawa T, Tarui S and Griffin JD: Expression and functional role of the proto-oncogene c-kit in acute myeloblastic leukemia cells. Blood 78: 2962-2968, 1991.

14. Natali PG, Nicotra MR, Winkler AB, Cavaliere R, Bigotti A and Ullrich A: Progression of human cutaneous melanoma is associated with loss of expression of c-kit proto-oncogene receptor. Int J Cancer 52: 197-201, 1992.

15. Berdel WE, de Vos S, Maurer J, Oberberg D, von Marschall Z, Schroeder JK, Li J, Ludwig WD, Kreuser ED, Thiel E, et al: Recombinant human stem cell factor stimulates growth of a human glioblastoma cell line expressing c-kit protooncogene. Cancer Res 52: 3498-3502, 1992

16. Natali PG, Nicotra MR, Sures I, Mottolese M, Botti C and Ullrich A: Breast cancer is associated with loss of the c-kit oncogene product. Int J Cancer 52: 713-717, 1992.

17. Hida T, Ueda R, Sekido Y, Hibi K, Matsuda R, Ariyoshi Y, Sugiura T, Takahashi T and Takahashi T: Ectopic expression of c-kit in small-cell lung cancer. Int J Cancer Suppl 8: 108-109, 1994

18. Hines SJ, Organ C, Kornstein MJ and Krystal GW: Coexpression of the c-kit and stem cell factor genes in breast carcinomas. Cell Growth Differ 6: 769-779, 1995.

19. Bokemeyer C, Kuczyk MA, Dunn T, Serth J, Hartmann K, Jonasson J, Pietsch T, Jonas U and Schmoll HJ: Expression of stem-cell factor and its receptor c-kit protein in normal testicular tissue and malignant germ-cell tumours. J Cancer Res Clin Oncol 122: 301-306, 1996.

20. Krystal GW, Hines SJ and Organ CP: Autocrine growth of small cell lung cancer mediated by coexpression of c-kit and stem cell factor. Cancer Res 56: 370-376, 1996

21. Montone KT, van Belle P, Elenitsas R and Elder DE: Protooncogene c-kit expression in malignant melanoma: Protein loss with tumor progression. Mod Pathol 10: 939-944, 1997.

22. Tian Q, Frierson HF Jr, Krystal GW and Moskaluk CA: Activating c-kit gene mutations in human germ cell tumors. Am J Pathol 154: 1643-1647, 1999.

23. Feng F, Liu XH, Xie Q, Liu WQ, Bai CG and Ma DL: Expression and mutation of c-kit gene in gastrointestinal stromal tumors. World J Gastroenterol 9: 2548-2451, 2003.

24. Bellone G, Smirne C, Carbone A, Buffolino A, Scirelli T, Prati A, Solerio D, Pirisi M, Valente G, Nano M and Emanuelli G $\mathrm{KIT} / \mathrm{stem}$ cell factor expression in premalignant and malignant lesions of the colon mucosa in relationship to disease progression and outcomes. Int J Oncol 29: 851-859, 2006.

25. Quinlan RA, Schiller DL, Hatzfeld M, Achtstätter T, Moll R, Jorcano JL, Magin TM and Franke WW: Patterns of expression and organization of cytokeratin intermediate filaments. Ann N Y Acad Sci 455: 282-306, 1985 .

26. Moll R, Schiller DL and Franke WW: Identification of protein IT of the intestinal cytoskeleton as a novel type I cytokeratin with unusual properties and expression patterns. J Cell Biol 111: 567-580, 1990.

27. Yamagishi H, Imai Y, Okamura T, Fukuda K, Ono Y, Ban S, Inoue $\mathrm{T}$ and Ueda Y: Aberrant cytokeratin expression as a possible prognostic predictor in poorly differentiated colorectal carcinoma. J Gastroenterol Hepatol 28: 1815-1822, 2013.
28. Varadhachary GR, Abbruzzese JL and Lenzi R: Diagnostic strategies for unknown primary cancer. Cancer 100: 1776-1785, 2004.

29. Kirchner T, Müller S, Hattori T, Mukaisyo K, Papadopoulos T, Brabletz T and Jung A: Metaplasia, intraepithelial neoplasia and early cancer of the stomach are related to dedifferentiated epithelial cells defined by cytokeratin-7 expression in gastritis. Virchows Arch 439: 512-522, 2001.

30. Slaughter DP, Southwick HW and Smejkal W: Field cancerization in oral stratified squamous epithelium; clinical implications of multicentric origin. Cancer 6: 963-968, 1953.

31. Luo Y, Yu M and Grady WM: Field cancerization in the colon: A role for aberrant DNA methylation? Gastroenterol Rep (Oxf) 2: 16-20, 2014

32. Lyda MH, Noffsinger A, Belli J and Fenoglio-Preiser CM: Microsatellite instability and K-ras mutations in patients with ulcerative colitis. Hum Pathol 31: 665-671, 2000.

33. Leedham SJ, Graham TA, Oukrif D, McDonald SA, Rodriguez-Justo M, Harrison RF, Shepherd NA, Novelli MR, Jankowski JA and Wright NA: Clonality, founder mutations, and field cancerization in human ulcerative colitis-associated neoplasia. Gastroenterology 136: 542-550.e6, 2009.

34. Koizumi K, Alonso S, Miyaki Y, Okada S, Ogura H, Shiiya N, Konishi F, Taya T, Perucho M and Suzuki K: Array-based identification of common DNA methylation alterations in ulcerative colitis. Int J Oncol 40: 983-994, 2011.

35. Galandiuk S, Rodriguez-Justo M, Jeffery R, Nicholson AM, Cheng Y, Oukrif D, Elia G, Leedham SJ, McDonald SA, Wright NA and Graham TA: Field cancerization in the intestinal epithelium of patients with Crohn's ileocolitis. Gastroenterology 142: 855-864.e8, 2012.

36. Lochhead P, Chan AT, Nishihara R, Fuchs CS, Beck AH, Giovannucci E and Ogino S: Etiologic field effect: Reappraisal of the field effect concept in cancer predisposition and progression. Mod Pathol 28: 14-29, 2015.

37. Facista A, Nguyen H, Lewis C, Prasad AR, Ramsey L, Zaitlin B, Nfonsam V, Krouse RS, Bernstein H, Payne CM, et al: Deficient expression of DNA repair enzymes in early progression to sporadic colon cancer. Genome Integr 3: 3, 2012.

38. Harbaum L, Pollheimer MJ, Kornprat P, Lindtner RA, Schlemmer A, Rehak P and Langner C: Keratin 7 expression in colorectal cancer-freak of nature or significant finding? Histopathology 59: 225-234, 2011

39. Park SY, Kim HS, Hong EK and Kim WH: Expression of cytokeratins 7 and 20 in primary carcinomas of the stomach and colorectum and their value in the differential diagnosis of metastatic carcinomas to the ovary. Hum Pathol 33: 1078-1085, 2002.

40. Besmer P, Murphy JE, George PC, Qiu FH, Bergold PJ, Lederman L, Snyder HW Jr, Brodeur D, Zuckerman EE and Hardy WD: A new acute transforming feline retrovirus and relationship of its oncogene $v$-kit with the protein kinase gene family. Nature 320: 415-421, 1986

41. Yarden Y, Kuang WJ, Yang-Feng T, Coussens L, Munemitsu S, Dull TJ, Chen E, Schlessinger J, Francke U and Ullrich A: Human proto-oncogene c-kit: A new cell surface receptor tyrosine kinase for an unidentified ligand. EMBO J 6: 3341-3351, 1986.

42. Ashman LK: The biology of stem cell factor and its receptor C-kit. Int J Biochem Cell Biol 31: 1037-1051, 1999.

43. Rönnstrand L: Signal transduction via the stem cell factor receptor/c-Kit. Cell Mol Life Sci 61: 2535-2548, 2004.

44. Preto A, Moutinho C, Velho S, Oliveira C, Rebocho AP, Figueiredo J, Soares P, Lopes JM and Seruca R: A subset of colorectal carcinomas express c-KIT protein independently of BRAF and/or KRAS activation. Virchows Arch 450: 619-626, 2007.

45. Sammarco I, Capurso G, Coppola L, Bonifazi AP, Cassetta S, Delle Fave G, Carrara A, Grassi GB, Rossi P, Sette C and Geremia R: Expression of the protooncogene c-KIT in normal and tumor tissues from colorectal carcinoma patients. Int J Colorectal Dis 19: 545-553, 2004.

46. Friederichs J, von Weyhern CW, Rosenberg R, Doll D, Busch R, Lordick F, Siewert JR and Sarbia M: Immunohistochemical detection of receptor tyrosine kinases c-kit, EGF-R, and PDGF-R in colorectal adenocarcinomas. Langenbecks Arch Surg 395: 373-379, 2010

47. Reed J, Ouban A, Schickor FK, Muraca P, Yeatman T and Coppola D: Immunohistochemical staining for c-Kit (CD117) is a rare event in human colorectal carcinoma. Clin Colorectal Cancer 2: 119-122, 2002 
48. Medinger M, Kleinschmidt M, Mross K, Wehmeyer B, Unger C, Schaefer HE, Weber R and Azemar M: c-kit (CD117) expression in human tumors and its prognostic value: An immunohistochemical analysis. Pathol Oncol Res 16: 295-301, 2010.

49. Toyota M, Hinoda Y, Takaoka A, Makiguchi Y, Takahashi T Itoh F, Imai $\mathrm{K}$ and Yachi A: Expression of c-kit and kit ligand in human colon carcinoma cells. Tumour Biol 14: 295-302, 1993.

50. Lahm H, Amstad P, Yilmaz A, Borbenyi Z, Wyniger J, Fischer JR, Suardet L, Givel JC and Odartchenko N: Interleukin 4 down-regulates expression of c-kit and autocrine stem cell factor in human colorectal carcinoma cells. Cell Growth Differ 6: $1111-1118,1995$.

51. Kitamura T, Kometani K, Hashida H, Matsunaga A, Miyoshi H, Hosogi H, Aoki M, Oshima M, Hattori M, Takabayashi A, et al: SMAD4-deficient interstinal tumors recruit CCR1+ myeloid cells that promote invasion. Nat Genet 39: 467-475, 2007.
52. Kitamura T, Fujishita T, Loetscher P, Revesz L, Hashida H, Kizaka-Kondoh S, Aoki M and Taketo MM: Inactivation of chemokine (C-C motif) receptor 1 (CCR1) suppresses colon cancer liver metastasis by blocking accumulation of immature myeloid cells in a mouse model. Proc Natl Acad Sci USA 107: 13063-13068, 2010.

53. Yilmaz E, Celik O, Simsek Y, Turkcuoglu I, Celik E, Gül M, Hascalik S and Aydin NE: c-Kit proto-oncogene expression in endometrial hyperplasia and endometrial cancer. Arch Gynecol Obstet 286: 197-200, 2012. 